\title{
Pharmacological and Clinical Evidence for the Use of Low- Molecular-Weight Heparins in Acute Coronary Syndromes
}

\author{
Guido Aranha Rosito, Otávio Berwanger da Silva, Jorge Pinto Ribeiro
}

Porto Alegre, RS - Brazil

\begin{abstract}
Acute coronary syndromes comprise clinical entities with variable prognoses, such as non-Q-wave acute myocardial infarction and unstable angina ${ }^{1-4}$. The unification of different manifestations of myocardial ischemia under a single term, even though questionable, reflects their similar pathophysiology. Erosion, fissure, or rupture of a relatively small atherosclerotic plaque ${ }^{5-7}$, which usually obstructs less than $50 \%$ of the arterial lumen ${ }^{8-10}$, promotes platelet activation and thrombin generation, forming a thrombus ${ }^{11,12}$.

Therefore, inhibition of the thrombin activity with heparin associated with a platelet aggregation inhibitor, such as aspirin, seems to be a rational approach. This hypothesis has been tested in several randomized studies ${ }^{13-17}$, with results favoring the use of this combination, even though the efficacy of heparin has been questioned. The metaanalysis by Oler et $\mathrm{al}^{18}$ confirmed these findings, showing that heparin in combination with aspirin reduces the combined outcome of death and acute myocardial infarction by $33 \%$. It is noteworthy that, isolated, the studies included in this review had methodological limitations and heterogeneous results. In addition, clinical and practical disadvantages of heparin use, such as the need for monitoring the activated partial thromboplastin time, the little predictable anticoagulant response, and the induction of thrombocytopenia, has led to an increased interest in low-molecular-weight heparins ${ }^{19,20}$. Recently, the efficacy of these drugs in unstable angina and acute myocardial infarction without elevation of the ST segment has been tested in several randomized studies ${ }^{21-27}$, among which are FRISC $^{22}$, FRISC II ${ }^{23}$, FRIC $^{24}$, ESSENCE ${ }^{25}$, FRAXIS ${ }^{26}$, and TIMI $11 \mathrm{~B}^{27}$. The analysis of the above cited studies
\end{abstract}

Hospital de Clínicas de Porto Alegre and Faculdade de Medicina da Universidade Federal do Rio Grande do Sul

Mailing address: Guido Aranha Rosito - Serviço de Cardiologia - Hospital de Clínicas de Porto Alegre - Rua Ramiro Barcelos, 2350 - 90035-007 - Porto Alegre, RS, Brazil, E-mail: guidorosito@cpovo.net

English version by Stela Maris C. e Gandour suggests a differentiated efficacy for low-molecular-weight heparins in acute coronary syndromes. The discrepant results could be explained by pharmacological characteristics of each low-molecular-weight heparin or the characteristics of each study. In this study, we analyze the pharmacological and clinical evidence that support the use of low-molecular-weight heparins in acute coronary syndromes.

\section{Comparison of the pharmacology of low-mole- cular-weight heparins}

The knowledge of the fundamental pharmacological characteristics of low-molecular-weight heparins should provide theoretical bases for the hypotheses to be tested in clinical trials, in the search for the best evidence, in addition to rationalizing and individualizing the therapeutics ${ }^{28-30}$. Several theoretical advantages in the pharmacology of lowmolecular-weight heparins as compared with that of unfractionated heparin have been stressed. These advantages comprise a more predictable and long-lasting anticoagulant effect. However, this does not characterize low-molecularweight heparins as a homogeneous group. Some pharmacodynamic and pharmacokinetic peculiarities of each drug could explain the differences in efficacy in the treatment of coronary artery diseases.

The first report on a process to obtain low-molecularweight heparin dates from the $60 \mathrm{~s}$ and was written by a Brazilian scientist, Dietrich ${ }^{31-33}$. Part of the anticoagulant effect of low-molecular-weight heparins is due to the activation of antithrombin (formerly known as antithrombin III), which is the major mechanism of action of unfractionated heparin ${ }^{34}$. However, unlike conventional heparin, lowmolecular-weight heparins have the highest activity against factor Xa, which inhibits the conversion of prothrombin to thrombin, resulting in a higher Xa/IIa ratio ${ }^{35}$. Therefore, the major mechanism of action of low-molecular-weight heparins precedes the thrombin stage, impairing its generation.

In addition to this major mechanism of action, others 
may also contribute to the antithrombotic effect of lowmolecular-weight heparins, such as the release of tissue factor inhibitor, the modulation of the vascular endothelium, and the stimulation of fibrinolysis. In addition, in vitro studies have suggested that these drugs have antiplatelet action, via inhibition of von Willebrand factor and the expression of $\mathrm{P}$-selectin ${ }^{36,37}$.

The major pharmacokinetic differences between lowmolecular-weight heparins and unfractionated heparin are basically explained by a smaller interaction with plasmatic protein, endothelial cells, platelets, and macrophages ${ }^{38}$, resulting in greater bioavailability. Low-molecular-weight heparins undergo reduced hepatic metabolism and slow and preponderant renal excretion, which results in a 2- to 4fold longer half-life. The best bioavailability, the doseindependent excretion, and the smaller affinity for proteins result in a predictable anticoagulant response (tab. I). Therefore, laboratory monitoring is not required in most patients, except in those with renal failure and weighing less than $50 \mathrm{~kg}$ or more than $80 \mathrm{~kg}^{39}$, for whom measurement of factor Xa may be useful.

The major risk associated with the use of low-molecular-weight heparins is the formation of hematoma at the site of drug injection. In the clinical trials previously cited, the incidence of major bleeding was acceptable and ranged from 0 to $6.5 \%$, and no relevant clinical differences between low-molecular-weight and unfractionated heparins were observed ${ }^{40}$. Minor bleeding, on the other hand, was more common when low-molecular-weight heparins were used. In the ESSENCE Study ${ }^{25}$, an episode of minor bleeding was found for every 21 patients receiving enoxaparin; in the FRISC Study ${ }^{22}$, however, this number was 12 . This difference, however, was basically due to hematomas at the sites of drug injection. Other undesired events, such as thrombocytopenia and allergic reactions, were rare in different studies, with rates lower than $1 \%$. The great disadvantage of the use of low-molecular-weight heparins as compared with that of unfractionated heparin is the absence of an antidote with a dose-dependent response. However, protamine may be used to antagonize part of the action of low-molecular-weight heparins.

Low-molecular-weight heparins have structural and pharmacological differences that, theoretically, may account for the different results obtained in the trials of acute ischemic syndromes. Low-molecular-weight heparins

\begin{tabular}{|ll|}
\hline $\begin{array}{l}\text { Table I - Mechanisms responsible for the pharmacokinetic } \\
\text { advantages of low-molecular-weight heparins as compared with } \\
\text { unfractionated heparin }\end{array}$ \\
\hline Advantag & Mechanism \\
\hline $\begin{array}{l}\text { More predictable anticoagulant } \\
\text { response }\end{array}$ & $\begin{array}{l}\text { Lower binding to plasma } \\
\text { proteins } \\
\text { Detter bioavailability } \\
\text { Longer half-life }\end{array}$ \\
\hline Adapted from Weitz JI. N Engl J Med 1997; 337: 688-97. \\
\hline
\end{tabular}

Low-molecular-weight heparins in acute coronary syndromes

are obtained from heparin through different physical or chemical processes, or both. Nadroparin and dalteparin are obtained through deamination cleavage with nitrous oxide, and enoxaparin is obtained through benzylation and alkaline treatment.

The pharmacokinetics of these 3 substances also show differences (tab. II). The absorption of nadroparin is slower than that of dalteparin, which, in turn, is slower than that of enoxaparin. Dalteparin has the shortest half-life and enoxaparin the longest. The antifactor $\mathrm{Xa} / \mathrm{II}$ a ratio, which is the most important pharmacodynamic characteristic in this class of anticoagulants, is higher for enoxaparin, whose value is twice or more than twice that of dalteparin and similar to that of nadroparin. The importance of the action upon factor $\mathrm{Xa}$ in the treatment of acute ischemic syndromes has not yet been totally clarified. On the basis of the results of the FRIC (dalteparin) ${ }^{24}$ and the TIMI 11B (enoxaparin $)^{27}$ studies, we can observe that patients treated with enoxaparin had higher levels of antifactor Xa activity (0.50.6 anti-Xa UI/mL) as compared with those who received dalteparin $(0.35-0.37 \mathrm{UI} / \mathrm{mL})$. This difference suggests that a suboptimal anticoagulant effect may have occurred in the FRIC study ${ }^{24}$, which may have contributed to the absence of benefit with the use of dalteparin as compared with that of regular heparin. Another biochemical parameter that has recently been the goal of experimental and clinical research is the action of low-molecular-weight heparins upon the von Willebrand factor. The early elevation of the levels of this factor has been associated with a higher incidence of cardiovascular events, and enoxaparin has managed to block this mechanism ${ }^{41}$, which the conventional heparin could not do. The pharmacokinetic and pharmacodynamic profiles of enoxaparin seem more favorable (tab. II), because this drug is more rapidly absorbed, has a longer action and a higher antifactor $\mathrm{Xa} / \mathrm{II}$ a ratio as compared with nadroparin and dalteparin. These profiles may explain the higher efficacy of enoxaparin as compared with that of the unfractionated heparin.

\section{Evidence of randomized and controlled studies}

Some initial studies have compared low-molecularweight heparins with placebo. The pioneering study by Gurfinkel et al ${ }^{21}$ tested the effect of nadroparin associated with acetylsalicylic acid in the treatment of 211 patients with acute coronary syndromes. On the intention-to-treat analysis, little efficacy was observed for the outcome fatal

\begin{tabular}{|lcccc|}
\hline $\begin{array}{c}\text { Table II - Molecular weight and pharmacological characteristics } \\
\text { of low-molecular-weight heparins in humans }\end{array}$ \\
\hline & $\begin{array}{c}\text { Molecular } \\
\text { weight }\end{array}$ & $\begin{array}{c}\text { Bioavai- } \\
\text { lability }\end{array}$ & Half-life & $\begin{array}{r}\text { Xa/IIa } \\
\text { ratio }\end{array}$ \\
\hline Enoxaparin & 3000 & $91 \%$ & $4.5 \mathrm{~h}$ & 3.9 \\
Nadroparin & 3000 & $67 \%$ & $3 \mathrm{~h}$ & 3.5 \\
Dalteparin & 5400 & $83 \%$ & $2.3 \mathrm{~h}$ & 2.2 \\
\hline
\end{tabular}


refractory angina. No patient receiving low-molecularweight heparin had the outcome myocardial infarction as compared with $9.5 \%$ of the group treated only with aspirin. This study, due to its low statistical power and low incidence of events, should be considered preliminary evidence.

The FRISC study ${ }^{22}$ randomized 1,506 patients to receive, in addition to the antianginal treatment and acetylsalicylic acid, dalteparin or placebo. At the end of 6 months of treatment, a reduction in the outcome of combined death and acute myocardial infarction was observed. This benefit remained significant after 40 days of treatment, but was lost after 150 days of follow-up.

The FRISC II study had a 2 -armed design, providing 2 simultaneous comparisons: dalteparin versus placebo, and conservative strategy versus invasive strategy. A difference favoring dalteparin for the combined outcome of death due to all causes and myocardial infarction in 1 month was observed. However, after 3 and 6 months, the formerly found difference lost its significance ${ }^{23}$.

The FRIC study was the first large randomized study $(n=1,482)$ comparing low-molecular-weight and unfractionated heparins associated with acetylsalicylic acid in the treatment of unstable angina and myocardial infarction without elevation of the ST segment ${ }^{24}$. In the acute phase (6 days), no difference between dalteparin and conventional heparin was observed in regard to an outcome of total mortality, myocardial infarction, and recurrent angina. Between 6 and 45 days, the rate of combined events was $12.3 \%$ for both groups (intervention and control), and the conclusion was that dalteparin did not provide any additional benefit to the control treatment.

In the ESSENCE study ${ }^{25}, 3,171$ patients with unstable angina and acute myocardial infarction without elevation of the ST segment were randomized to receive enoxaparin or unfractionated heparin. After 14 days, a reduction in the primary outcome combining total mortality, infarction, and angina occurred. This benefit was mainly due to a $17 \%$ reduction in recurring angina. The effect on total mortality and acute myocardial infarction, when assessed separately, did not reach statistical significance. The follow-up showed that the beneficial effect of enoxaparin was maintained after 1 year of treatment. For the first time, an advantage was shown in the combination of relevant outcomes of one lowmolecular-weight heparin when compared with that of the conventional heparin in acute coronary syndrome.

The results of the FRAXIS study ${ }^{26}$ have been recently published. In this study, 3,468 patients were randomized into 3 groups as follows: one group received nadroparin for 6 days, the second group received nadroparin for 14 days, and the third group received unfractionated heparin for 6 days. After 6, 14, and 90 days, the absolute rate of a combined outcome (total mortality, acute myocardial infarction, recurring angina, and the need for revascularization) was similar for the 3 groups.

In the clinical trial TIMI $11 \mathrm{~B}^{27}, 4,021$ patients were randomized for testing the hypothesis that enoxaparin is superior to unfractionated heparin during the acute phase ( 8 days) and superior to placebo in 35 days in regard to combined outcomes. By the end of 14 days, a reduction in the incidence of death, infarction, and revascularization occurred. This initial beneficial effect of enoxaparin persisted after 43 days of treatment, and it was not necessary to extend the treatment beyond the acute phase.

Antman et $\mathrm{al}^{42}$ carried out a meta-analysis (TESSMA) comparing enoxaparin with unfractionated heparin, using data from the ESSENCE and TIMI 11B studies. Enoxaparin, when compared with unfractionated heparin, reduced by $23 \%$ the outcome of death and acute myocardial infarction in 8 days. The incidence of bleeding, however, was increased among those patients receiving enoxaparin.

Eikelboom et al ${ }^{43}$ recently published meta-analyses comparing the use of unfractionated heparin and placebo, of unfractionated heparin and low-molecular-weight heparins in the hospital phase, and the home use of lowmolecular-weight heparin. The results suggest that, in unstable angina and non-Q-wave infarction, a superiority of any type of heparin as compared with placebo exists, an equivalence between unfractionated and low-molecularweight heparins also exists, and no advantage in extending the treatment beyond the initial period could be observed. The meta-analysis of the comparative studies between lowmolecular-weight and unfractionated heparins has been criticized because some of these studies have shown a low incidence of events. Therefore, this meta-analysis has a low statistical power for detecting differences between the treatments, leading to a type II error.

\section{Methodological limitations}

Based on the results of these clinical trials, one may conclude that low-molecular-weight heparins are at least as efficient as unfractionated heparin, and that enoxaparin was the only low-molecular-weight heparin to show any superiority to unfractionated heparin ${ }^{44}$. These findings suggest that differences in efficacy may exist between the low-molecular-weight heparins ${ }^{29}$. Both pharmacological and methodological differences could explain the discrepant results between the randomized clinical trials (tabls. II, III, and IV).

In regard to the criterion of selection in the ESSENCE ${ }^{25}$ and TIMI $11 \mathrm{~B}^{27}$ studies, the randomized patients had had their episode of chest pain up to 24 hours before, and in the FRIC ${ }^{24}$ and FRAXIS ${ }^{26}$ studies, up to 72 hours before. Another difference concerns the risk of the patients selected in each study. Theoretically, the higher the absolute risk of the individual, the higher the potential benefit of a therapeutical or preventive intervention ${ }^{28}$. In the 2 studies that showed the superiority of enoxaparin in relation to unfractionated heparin, the sample had a greater potential risk. For example, in the ESSENCE ${ }^{25}$ and in the TIMI 11B ${ }^{27}$ studies, a higher proportion of patients with non-Q-wave acute myocardial infarction existed (21\% and $34 \%$, respectively) as compared with those individuals in the FRIC study ${ }^{24}$, in which only $16 \%$ had this diagnosis. In 
addition, the rates of myocardial revascularization, which are also a marker of risk, varied in the different clinical trials. For example, the cumulative rate of revascularization, both in the intervention arm and in the placebo arm of the FRIC study ${ }^{24}$, was approximately $19 \%$, which is substantially lower than the values found in the ESSENCE study ${ }^{25}$, which were $32.2 \%$ and $27 \%$ in the control and intervention groups, respectively.

The dosages of low-molecular-weight heparins and those of unfractionated heparin varied from study to study; therefore, the intensity of anticoagulation may have varied in the different clinical trials.

\section{Economic feasibility}

From the perspective of a medical practice based not only on evidence but also on cost-effectiveness, more and more emphasis has been given to economical analyses ${ }^{45}$. Satisfactory evidence already existed that low-molecularweight heparins were more cost-effective than conventional heparin in other clinical situations, such as treatment and prevention of deep venous thrombosis ${ }^{46-48}$. In 1998, an economic substudy was published based on the ESSENCE clinical trial, involving 923 patients ${ }^{49}$. The total medical cost per patient was not different for enoxaparin and conventional heparin in the initial hospitalization (U\$ 11,857 and U\$ 12,620 , respectively). In 30 days of treatment, however, a cumulative savings of U $\$ 1,172$ per patient was obtained with the use of enoxaparin. The most appropriate delineation for assessing the question would be the cost-utility of the analysis (which considers quantity and quality of life); however, in its absence, we may consider that enoxaparin has an economic advantage in relation to unfractionated heparin. A comparative analysis between direct costs of using unfractionated and low-molecularweight heparins carried out in the Hospital de Clínicas de Porto Alegre showed a similar cost for the different heparins. Considering the expenses with drugs, laboratory, and use of infusion pumps, the results favored lowmolecular-weight heparins. With this favorable result, a cost-effectiveness analysis was considered unnecessary.

\section{Conclusion}

Based on the revised evidence, we may conclude that low-molecular-weight heparins have class I recommendation in the treatment of acute coronary syndromes (ie, indication based on evidence obtained in randomized studies properly delineated with clinically relevant outcomes and statistical power). To date, enoxaparin is the only low-molecular-weight heparin that has proved to be superior to unfractionated heparin, dalteparin and nadroparin being at least as effective as the unfractionated heparin (fig. 1). This suggests that enoxaparin should be part of the current

\begin{tabular}{|llllll|}
\hline \multicolumn{6}{|c|}{ Table III - Characteristics of the randomized studies of acute phase comparing low-molecular-weight heparins with unfractionated heparin in } \\
unstable angina
\end{tabular}

\begin{tabular}{|c|c|c|c|c|c|}
\hline Study & Outcome & Follow-up & LMWH & $\mathrm{UH}$ & NNT (95\%Confidence interval) \\
\hline FRIC & Death/AMI/angina & 6 days & $9.3 \%$ & $7.6 \%$ & 59 (NND 90 until $\boldsymbol{\square}$ until NNT 22) \\
\hline ESSENCE & Death/AMI/angina & 14 days & $16.6 \%$ & $19.7 \%$ & $31(17$ until 191) \\
\hline FRAXIS & Death/AMI/angina & 14 days & $17.8 \%$ & $18.1 \%$ & 333 (NND 35 until $\boldsymbol{\square}$ until NNT 29) \\
\hline TIMI 11B & Death/AMI/revascularization & 14 days & $24.6 \%$ & $26.2 \%$ & 62 (NND 91 until $\boldsymbol{\square}$ until NNT 23) \\
\hline
\end{tabular}


standardized treatment for unstable angina and non-STsegment elevation myocardial infarction; this was corroborated by the recent joint guidelines of the American Heart Association and American College of Cardiology ${ }^{50}$. Unfractionated heparin would be used in high-risk patients undergoing angiography or angioplasty, and receiving platelet glycoprotein IIb/IIIa receptor antagonists, even though studies are being carried out on the use of low-molecularweight heparins in coronary angioplasty. In addition, lowmolecular-weight heparins are an attractive option for acute coronary syndromes, because monitoring is not necessary in most patients and the use of intravenous infusion pumps and constant adjustments of the doses are not required.

Direct comparisons between enoxaparin, dalteparin, and nadroparin are limited by pharmacological and methodological differences existing between the studies, and these direct comparisons are only possible with comparative randomized studies designed for this purpose.

In the context of the contemporary management of acute coronary syndromes, low-molecular-weight heparins may be used according to the risk stratification of patients. Low-risk patients should receive acetylsalicylic acid, betablockers, nitrates, and undergo noninvasive tests to induce ischemia. Low-molecular-weight heparins should be added to the treatment of intermediate-risk patients. Finally,

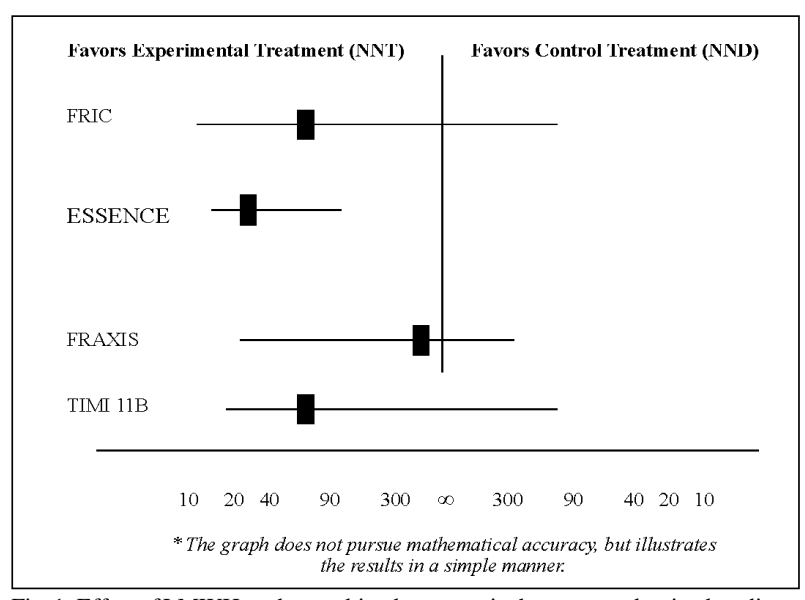

Fig. 1-Effect of LMWH on the combined outcome in the great randomized studies

high-risk patients, characterized by extensive alterations on the electrocardiogram and an increase in the levels of serum markers of ischemia and lesion, could receive, in addition to low-molecular-weight heparins, platelet glycoprotein IIb/ IIIa receptor inhibitors by intravenous via, and should be considered for myocardial revascularization. In this case, unfractionated heparin may be chosen until new evidence shows which management is more effective.

\section{References}

1. Simoons ML, Boersma E, van der Zwaan C, Deckers JW. The challenge of acute coronary syndromes. Lancet 1999; 353(suppl II): 1-4.

2. Theroux P, Fuster V. Acute coronary syndromes. Unstable angina and non-Q wave myocardial infarction. Circulation 1998; 97: 1195-206.

3. Cannon CP, Mccabe CH, Stone PH, et al. The electrocardiogram predicts oneyear outcome of patients with unstable angina and non-Q wave myocardial infarction: results of the TIMI III Registry ECG Ancillary Study. J Am Coll Cardiol 1997; 30: 133-40.

4. Nyman I, Areskog M, Areskog NH, Swahn E, Wallentin L. Very early risk stratification electrocardiography at rest in men with suspectes unstable coronary heart disease. The RISC Study Group. J Intern Med 1993; 234: 293-301.

5. Libby P. Molecular bases of the acute coronary syndromes. Circulation 1995; 91 : 284- 51.

6. Fuster V, Gotto AM, Libby P. Matching the intensity of risk factor management with the hazard for coronary disease events. Pathogenesis of coronary disease: the biologic role of risk factors. J Am Coll Cardiol 1996; 27: 964-76.

7. Davies MJ, Richardson PD, Woolf N, et al. Risk of thrombosis in human atherosclerotic plaques: role of extracellular lipid, macrophages, and smooth muscle content. Br Heart J 1993; 69: 377-81.

8. Ambrose JA, Tannenbaum M, Alexpouloos D, et al. Angiographic progression of coronary artery disease and the development of myocardial infarction. J Am Coll Cardiol 1988; 12: 56-62.

9. Little WC, Connstanninescu M, Applegate RJ, et al. Can coronary angiography predict the site of a subsequent myocardial infarction in patientes with mild-tomoderate coronary artery disease? Circulation 1998; 78: 1157-66.

10. Stary HC, Chandler AB, Dinsmore RE, et al. A definition of advanced type of atherosclerotic lesions and a histological classification of atherosclerosis. A report from the Committee on Vascular Lesions of the Council on Arteriosclerosis, American Heart Association. Circulation 1995; 92: 1355-74.

11. Fernandez-Ortiz A, Badimon J, Falk E, et al. Characterization of the relative thrombogenicity of atherosclerotic plaque components: implications for consequences of plaque rupture. J Am Coll Cardiol 1994; 23: 1562-9.

12. FalkE, Shah PK, Fuster V. Coronary plaque disruption. Circulation 1995; 92: 657-71.
13. The RISC Study Group. Risk of myocardial infarction and death during treatment with low dose asporin and intravenous heparin in men with unstable coronary artery disease. Lancet 1990; 336: 827-30.

14. Theroux P, Ouimet H, McCans J, et al. Aspirin, heparin or both to treat acute unstable angina. N Engl J Med 1988; 319: 1105-11.

15. Cohen M, Adams PC, Parry G, et al. Combination antithrombotic therapy in resting angina pectoris or non-Q wave myocardial infarction in preventing death and myocardial infarction. Am J Cardiol 1990; 66: 1287-92.

16. Cohen M, Adams PC, Parry G, et al. Combination antithrombotic therapy in resting angina and non- $\mathrm{Q}$ wave myocardial infarction in non prior aspirin users: primary endpoint analysis from the ATACS Trial. Circulation 1994; 89: 81-8.

17. Holdright $\mathrm{D}$, Patel D, Cunningham D, et al. Comparison of the effect of heparin and aspirin versus aspirin alone on transient myocardial ischemia and in-hospital prognosis in patientes with unstable angina. J Am Coll Cardiol 1994; 24: 39-45.

18. Oler A, Whooley MD, Oler J, Grady D. Adding heparin to aspirin reduces the incidence of myocardial infarction and death in patients with unstable angina: a meta-analysis. JAMA 1996; 276: 811-5.

19. Cairns JA, Lewis HD, Meade TW, et al. Antithrombotic agents in coronary artery disease. Fourth ACCP Consensus Conference on Antithrombotic Therapy. Chest 1995; 108(supll 4): 380S-400S.

20. Weitz JI. Low-molecular-weight heparins. N Engl J Med 1997; 337: 688-98.

21. Gurfinkel EP, Manos EJ, Mejaíl RI, et al. Low molecular weight heparin versus regular heparin or aspirin in the treatment of unstable angina and silent ischemia. J Am Coll Cardiol 1995; 26: 313-8.

22. FRISC Study Group. Low-molecular-weight heparin during instability in coronary artery disease (FRISC). Lancet 1996; 347: 561-8.

23. FRISC II Investigators. Long-term low molecular-mass heparin in unstable coronary-artery disease: FRISC II Prospective Randomised Multicentre Study. Lancet 1999; 354

24. Klein W, Buchwald A, Hillis SE, et al. Comparison of low-molecular weight heparin with unfractionated heparin acutely and with placebo for 6 weeks in the management of unstable coronary artery disease. Fragmin in unstable coronary artery disease study (FRIC). Circulation 1997; 96: 61-8.

25. Cohen M, Demers C, Gurfinkel EP, et al. A comparison of low-molecular-weight 
heparin with unfractionated heparin for unstable coronary artery disease. The efficacy and safety of subcutaneous enoxaparin in non-Q-wave coronary events study group (ESSENCE). N Engl J Med 1997; 337: 447-52.

26. The FRAXIS Study Group. Comparison of two treatment durations ( 6 days and 14 days) of a low molecular weight heparin with a 6 day treatment of unfractionated heparin in the initial management of unstable angina or non-Q wave myocardial infarction: FRAXIS (Fraxiparine in Ischaemic Syndrome). Eur Heart J 1999; 20: 1553-62.

27. Antman EM, McCabe CH, Gurfinkel EP, et al. Enoxaparin for the acute and chronic management of unstable angina/non-Q wave myocardial infarction: Results of TIMI 11B. Circulation 1999; 100: 1593-601.

28. Sackett DL, Rosemberg WM, Gray JAM, et al. Evidence based medicine: what it is and what it isn't. BMJ 1996; 312: 71-2.

29. Evidence-Based Medicine Working Group. Evidence-based medicine: a new approach to teaching the practice of medicine. JAMA 1992; 208: 2420-5.

30. Sackett DL, Haynes RB. On the need for evidence-based medicine. EvidenceBased Medicine 1995; 1: 4-5.

31. Dietrich CP, Nader HB, McDuffie CP. Eletrophocusing of heparin - Presence of 21 monomeric and dimeric molecular species in heparin preparations. Anais da Academia Brasileira de Ciências 1975; 47: 301-9.

32. Bianchini P, Osima B, Dietrich CP, et al. Pharmacological activities of heparins obtained from different tissues: enrichment of heparin fractions with high lipoprotein lipase, antihemolytic and anticoagulant activities by molecular sieving and antithrombin III affinity chromatography. Journal of Pharmacology and Experimental Therapeutics. 1992; 220: 406-10.

33. Bianchini P, Osima B, Parma B, et al. Lack of correlation between "in vitro" and "in vivo" antithrombotic activity of heparin fractions and related compounds: heparin sulfate as an antithrombotic agent "in vivo". Thrombosis Research 1985; 40: 597-607.

34. Harenberg J. Pharmacology of low-molecular-weight heparins. Semin Thromb Hemost 1990; 16(suppl): 12-8.

35. Huang ZF, Wun TC, Broze GJ Jr. Kinectics of factor Xa inhibition by tissue factor pathway inhibitor. J Biol Chem 1993; 268: 2650-5.

36. Sobel M, McNeill PM, Carlson PL, et al. Heparin inhibition on von Willebrand factordependet platelet function in vitro and in vivo. J Clin Invest 1991; 87: 1787-93.

37. de Roumeuf C, Mazurier C. Heparin binding assay of von Willebrand factor (vWF) in plasma mileu. Thromb Haemost 1993; 69: 436-40.
38. Young E, Wells P, Holloway S, Wietz J. Ex-vivo and in vitro evidence that lowmolecular-weight heparins exhibit less binding to plasma proteins than unfractionated heparin. Thromb Haemost 1994; 71: 300-4.

39. Bratt G, Tornebohm E, Lockner D, Bergstrom K. A human pharmacological study comparing conventional heparin and a low-molecular-weight heparin fragment. Thromb Haemost 1985; 53: 208-11.

40. Cohen M. Low-molecular-weight heparins in the management of unstable angina/ non-Q wave myocardial infarction. Sem Thromb Hemost 1999; 25: 113-21.

41. Montalescot G, Philippe, Annick A, et al. Early increase of von Willebrand factor predicts adverse outcome in unstable coronary artery disease. Benefical effects of enoxaparin. Circulation 1998; 98: 294-9.

42. Antman EM, Cohen M, Radley D, et al. Enoxaparin for unstable angina/non-Q wave myocardial infarction: Meta-analysis of TIMI 11B and ESSENCE. Circulation 1999; 100: 1602-8.

43. Eikelboom JW, Anand SS, Malmberg K, Weitz JI, Ginsberg JS, Yusuf S. Unfractioned heparin and low-molecular weight heparin in acute coronay syndrome without ST elevation: a meta-analysis. Lancet 2000; 355:1936-42

44. Natajaran MK. Unstable angina. Clinical Evidence 1999; 1: 454-64.

45. Laupacis A, Sackett Dl, Roberts RS. An assesment of clinically useful measures of the consequences of treatment. N Engl J Med 1988; 318: 1728-33.

46. Rodger M, Bredeson C, Wells PS, et al. Low molecular weight heparin was more cost-effective than unfractionated heparin for treating deep venous thrombosis in several clinical settings. CMJA 1998; 159: 931-8.

47. Bergqvist D, Lindgren B, Matzsch T, et al. Comparison of the cost of preventing postoperative deep venous thrombosis with either unfractionated or low molecular weight heparin. Br J Surg 1996; 83: 1548-52.

48. Hull RD, Raskob GE, Rosenbloom D, et al. Treatment of proximal vein thrombosis with subcutaneous low molecular weight heparin vs. Intravenous heparin. An economic perspective. Arch Int Med 1997; 157: 289-94.

49. Mark DB, Cowper PA, Berkowitz SD, et al. Economic assessment of low molecular weight heparin (enoxaparin) versus unfractionated heparin in acute coronary syndrome patients. Results from the ESSENCE randomized trial. Circulation 1998; 97: 1702-7.

50. Braunwald E, Antman EM, Beasley JW, et al. ACC/AHA guidelines for unstable angina and non-ST-segment elevation myocardial infarction. J Am Coll Cardiol 2000; 36: 970-1062. 